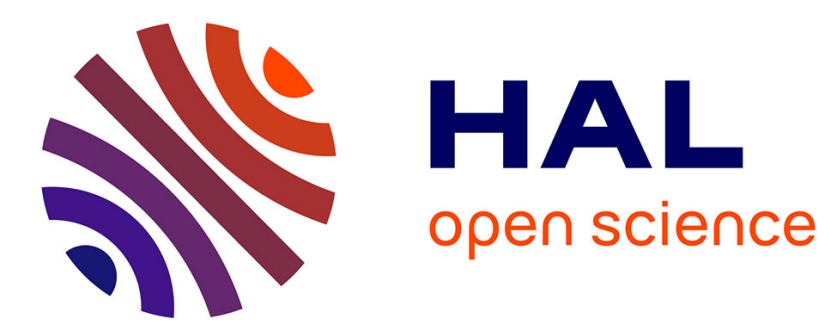

\title{
Le nouveau régime forestier au Québec Jean Pardé
}

\section{- To cite this version:}

Jean Pardé. Le nouveau régime forestier au Québec. Revue forestière française, 1988, 60 (5), pp.413414. 10.4267/2042/25910 . hal-03424762

\section{HAL Id: hal-03424762 https://hal.science/hal-03424762}

Submitted on 10 Nov 2021

HAL is a multi-disciplinary open access archive for the deposit and dissemination of scientific research documents, whether they are published or not. The documents may come from teaching and research institutions in France or abroad, or from public or private research centers.
L'archive ouverte pluridisciplinaire HAL, est destinée au dépôt et à la diffusion de documents scientifiques de niveau recherche, publiés ou non, émanant des établissements d'enseignement et de recherche français ou étrangers, des laboratoires publics ou privés. 


\section{LE NOUVEAU RÉGIME FORESTIER AU QUÉBEC *}

Si le Canada entier totalise 436 millions d'hectares de forêts, la part du Québec, dans ce total, est de 78 millions. Mais la forêt commercialement exploitable québécoise ne représente que 56 millions d'hectares, la récolte annuelle ètant de l'ordre de 30 millions de $\mathrm{m}^{3}$, représentant le plus souvent des coupes rases faites quasi gratuitement par de grandes compagnies forestières.

On sait le rôle capital que joue le bois dans l'économie québécoise, puisque les exportations des produits de la filière-bois représentent $24 \%$ des exportations de la province. C'est ainsi que la production québécoise de papier journal représente plus de $16 \%$ de la production mondiale.

Or, rien ne va plus maintenant, et le pire serait à venir, si rien n'était fait : la coupe dépasse largement la possibilité naturelle des forêts publiques ( $85 \%$ du territoire forestier) ; la demande industrielle est en progression constante; l'effort d'aménagement est très déficient, on demande une utilisation plus polyvalente de la forêt, etc...

C'est pourquoi l'Assemblèe nationale a adoptè, le 19 décembre 1986, un projet de loi devenu la "Loi sur les forêts", entrèe en vigueur le $1^{\text {er }}$ avril 1987, qui introduit un véritable et salutaire bouleversement dans la gestion des forêts québécoises.

Cette loi institue un véritable régime forestier, basé sur le respect d'une possibilité annuelle de coupes permettant un rendement soutenu, sur l'octroi à l'industrie de contrats d'approvisionnement couplant exploitation et aménagement forestier, partageant aussi de façon nouvelle la responsabilité en matière d'aménagement des forêts publiques. II s'agit, pour l'essentiel, de maintenir ou reconstituer le couvert forestier et de protéger l'ensemble des ressources du milieu forestier.

"Concrètement, le maintien du couvert forestier se traduit par l'obligation pour tout détenteur d'un permis de remettre en production le territoire où il a fait une intervention et ce, à un niveau de production au moins égal à celui du peuplement où l'intervention a eu lieu, et dans un délai prévu à l'avance dans son plan d'intervention, soumis préalablement au ministère pour approbation. Les traitements sylvicoles visant à promouvoir la régénération naturelle des forêts seront sans doute privilégiés parce que moins coûteux, mais le reboisement se fera aussi par plantation; cette année (1987), quelque 140 millions de plants seront mis en terre à cet effet en forêt publique".

\footnotetext{
- D'après l'article paru, sous ce titre, et signé G. Paillé et R. Deffrasnes dans le numero d'avril 1988 de la revıe canadienne LAubelle, editée par l'Ordre des Ingénieurs torestiers du Québec (2022 rue Lavoisier - Bureau 165. Sainte-Foy Québec G1N 4L5).
} 
Par ailleurs, les ressources aquatiques, fauniques, écologiques et récréatives bénéficient maintenant d'une protection spéciale. Avec chaque industriel est dorénavant signé "un contrat d'approvisionnement et d'aménagement forestier " précisant parfaitement ses droits mais aussi ses devoirs.

On le voit, il s'agit bien d'un heureux bouleversement, qui se traduit déjà dans les forêts. Un seul exemple : le Québec produisait, avant 1987, quelque 38 millions de plants forestiers chaque année. On en mettra en terre 250 millions dès 1988, l'objectif étant de passer sans plus tarder à 300 millions de plants annuels.

La Revue aura certainement l'occasion de revenir plus longuement sur ce sujet. Mais nous avons tenu à donner à nos lecteurs, sans plus tarder, une première information sur un événement capital dont l'impact réel se fera, du reste, sentir plutôt à long terme qu'au moment présent.

J.P.

\section{NOUVELLES DU QUÉBEC FORESTIER}

\section{Pesticides et forêts}

L'Aubelle de juin/juillet 1988 (il s'agit du bulletin de l'Ordre des Ingénieurs forestiers du Québec) publie un mémoire, émanant de l'Ordre, qui a été présenté à une commission parlementaire le 2 juin 1988.

En voici le résumé :

L'Ordre des Ingénieurs forestiers du Québec soutient que l'utilisation des pesticides en milieu forestier est parfois nécessaire, pour protéger la forêt contre l'invasion des insectes défoliateurs d'une part, et d'autre part pour contrôler la végétation concurrente qui envahit les jeunes plantations.

II souligne que l'utilisation de ces produits doit être considérée comme une solution de dernier recours, lorsque toutes les autres options d'intervention s'avèrent impossibles.

L'Ordre recommande que l'insecticide biologique Bacillus thuringiensis (BT) et le glyphosate soient utilisés sans étude d'impact en raison de leur sécurité et de leur efficacité reconnues, et que des efforts de recherche soient consentis afin de développer des solutions de rechange à leur utilisation en milieu forestier.

\section{Enseignement forestier supérieur}

D'importants travaux vont être effectués à la Faculté de Foresterie et de Géodésie de I'Université Laval. Combinés avec d'autres mesures (création de chaire notamment), ils doivent permettre à la Faculté - nous citons - : "de continuer à assurer le leadership exercé depuis plus de 75 ans dans l'enseignement et la recherche en foresterie au Canada français, ainsi que dans le monde francophone".

La première phase des travaux doit commencer à l'automne 1988. Elle s'élève à 4250000 dollars canadiens, soit environ 21250000 francs français. 